TranscUlturAl vol. 1, (4) 2011, 47-62.

http://ejournals.library.ualberta.ca/index.php/TC

\title{
Formula and "Fixity" in South Slavic Oral Epics: A defense of South Slavic poetic verse against literary accusations of mechanicalism
}

Lai-Tze Fan

Wilfrid Laurier University

The art of the oral epic has long suffered generalizations from the literary academe, which once assumed that the cultures from which oral epics came possessed a verbatim memory similar to their own (Ong 57). Such assumptions ceased when the conditions of a primary oral culture were made known, as initiated by epic poetry scholar Milman Parry. His doctoral dissertation showed that the oral epics of ancient Greece possess the same basic elements in theme and verse, suggesting that great works such as Homer's The Iliad were not as creatively brilliant as the academic world had then believed. In fact, the epic verse seemed to fit into a consistent pattern: each line is strictly hexametrical and made up of reoccurring phrases. Parry posited that a formula was used to compose epic poems.

Parry's theory prompted him and his successor Albert Lord to test it in a living (but already disappearing) oral culture during the 1930s-1950s - former Yugoslavia, which possessed a rich male-dominated tradition in the oral epic. The South Slavic poets at this time, the majority of whom were illiterate, helped to validate Parry's theory: the South Slavic oral epic proved to contain themes and phrases that reoccur, and each line of verse is metrical. However, in light of these studies, the South Slavic oral epic (and the oral epic in general) may also be deemed uncreative: the same formulas are used to compose the same verses; the same themes are used to create the same plots. John Miles Foley claims that such observations caused scholars to quarrel over "whether the demonstration of the compositional role of formulas and themes makes the poet a prisoner of his compositional idiom and thus turns great poems into mechanical tours-de-force" (Immanent Art xii). The question at hand stands thus: if the oral epic is "fixed," if it possesses formula, is it therefore an act of mechanical composition rather than true creative art?

The South Slavic oral epic tradition was originally established in "medieval times, before the Turkish conquests" (The Singer of Tales 16), when Christian courts had 
TranscUlturAl vol. 1, (4) 2011, 47-62.

http://ejournals.library.ualberta.ca/index.php/TC

supported the minstrel's art. After the Turkish were expelled, only "the local Moslem nobility [sic] with its rich estates had fostered this art, and since this local nobility was still alive in some districts, such as Novi Pazar, Bijelo Polje, and Bihać in the 1930's, it was still possible to obtain firsthand information about the practice" (The Singer of Tales 16). Oral epics continued to be culturally relevant as long as record-making (as provided through literacy) was unavailable to the majority of the community. Therefore, this paper concerns itself with the oral epic prior to literacy making an effect on South Slavic culture; the body of material being examined is the repertoire of oral epics studied by Milman Parry and Albert Lord during their fieldwork in former Yugoslavia in the 1930s, and 1940s and 1950s respectively. Sampled songs and poets (called singers, as they sing their poetry) examined here are originally found in the Parry Collection (housed at Harvard University) and Lord's foundational The Singer of Tales (1960). This paper analyzes these songs and singers through Lord's original observations in order to make its claim. It is not concerned with present-day South Slavic cultures, which, as they are no longer primarily oral cultures, are not suitable for study as cultures whose historical preservation is a matter of urgency. Therefore, I also do not concern my analysis with contemporary South Slavic singers who have carried on the tradition because, their communities now influenced by literacy, their means of learning the traditional art may have changed. Of course, the same songs have not been lost to them in these past fifty years, but would the tools of writing and recording be permitted to them, if they were to record all of the formulas and themes to be picked from as in a catalogue, they would never, as Lord argues, be deemed singers of this great tradition (The Singer of Tales $37)$.

It should be noted that prior to analysis by outside visitors to this culture, in this case, Lord, formulas and themes of these sung oral epics would not have been recorded for presentation or analysis, but remained cultural knowledge passed only through song. Recordings later made by Lord were purely for example's sake and by no means deemed official versions of songs. This is because singers often changed wording and even whole sections of songs at their will, as this paper will later discuss. Generally, these singers were actually unable to produce an identical version of a song they had sung moments before, simply because they had sung through improvisation rather than memory. Lord argues that, as the moment of composition for the poet is the actual performance, "the question "when would such and such an oral poem be performed?' has no meaning; the question should be 
TranscUlturAl vol. 1, (4) 2011, 47-62.

http://ejournals.library.ualberta.ca/index.php/TC

'when was the oral poem performed?"' (The Singer of Tales 13).

Thus, this defense begins by considering the complication with the concept of fixity in the South Slavic oral epic, which is precisely this: the artistic tradition was established in a primary oral culture, the attributes of which may be a new concept for literary minds. It is understandable why the literary mind may assume that the use of formula means that a mechanical tactic must be in use, and why this would in turn signify that the oral epic is not artistic but rather, fixed. Foley states that "since we obviously can't appreciate what we don't know, our perspective is fatally skewed from the very start" (How to Read an Oral Poem 28); indeed, the literary mind is not necessarily familiar with the notion of instant composition, perhaps considering it near unfathomable. The alien nature of the South Slavic oral epic seems to threaten the literate mind with its mind-boggling stratagem. The only way to elucidate the oral epic then, is with a literary conviction such as "the catalogue," which subjects the art form to literary conditions. Yet, according to A.R. Luria's research, the concept of classification and cataloguing cannot exist in a primary oral culture because this kind of abstract thought is not possible - the primary oral mind thinks strictly in situational, operational contexts (Ong 52). What literary minds must understand is that in such a culture, repetition is necessary for survival because it is the method through which history is retained and knowledge is transferred.

Formula and theme naturally result from the traditionalist demands of preservation in a primary oral culture, but this does not imply that they are memorized and then picked from, as in a catalogue. The traditional art form of the oral epic requires that the storyteller interiorize them so that their use is a matter of unconscious reflex. The South Slavic oral epic poet - the singer - utilizes the cultural knowledge he has ingrained from having been exposed to the traditional art form himself, and then passes on his culture through the art form. ${ }^{1}$ Traditional art, in this sense, implies that there is "a depth of meaning set into that literature, from its origin, by previous generations. Text and context are inseparable. Without a sympathetic knowledge of context, the text may be misunderstood" (The Singer Resumes the Tale 1). Let us examine why formula and theme reoccur (and are therefore deemed "fixed") by analyzing them and by considering how each helps the South Slavic singer compose the oral epic. By doing so, this paper aims to argue that the belief of mechanical

1 The male pronoun will be used throughout this paper in reference to the South Slavic oral epic solely because the tradition has historically been exclusive to male members of the community. 
TranscUlturAl vol. 1, (4) 2011, 47-62.

http://ejournals.library.ualberta.ca/index.php/TC

composition is flawed.

Lord defines the term theme as "the groups of ideas regularly used in telling in the formulaic style of traditional song" (The Singer of Tales 68). In turn, formula is the means through which the theme is assembled; Lord defines it as "a group of words which is regularly employed under the same metrical conditions to express a given essential idea" (Tradition-dependent 263). The analysis of themes is best explained by the process through which they are learned. Lord observed in Yugoslavia in the 1940s that a young South Slavic boy becomes aware of the musical tradition that surrounds him. He recognizes that the same idea and incidents are used in songs that are sung in his community, creating a concept of theming in his mind. When the boy begins to sing, he learns that themes are composed through a structural pattern of smaller units (which may be called subthemes) that will be the framework on which he will construct (The Singer of Tales 71). For instance, when composing the common theme of The Council (the theme in which an authoritative council is gathered), singers rely on building the theme through its specific subthemes; for example, "what preparations are made to receive the assembling host, and how each contingent arrives, what its heroes are wearing and what horses they are riding and in what order they appear" (The Singer of Tales 68).

As the grouping of subthemes creates larger themes, so the stringing of themes results in a narrative. Lord provides specific examples of themes and subthemes in order to examine how this occurs. In the subtheme, The Hero's Sorrow, disrupting the happiness of a character or a group of characters means that changes must be made in order to restore the peace. The council, for example, only gathers to make an authoritative decision when the king or nation is in trouble (The Singer of Tales 80). This subtheme contains the oral characteristics of agonism and empathy - it involves and requires characters' negative and positive emotions to create cause for action and to drive action in a plot.

The agonistic quality of this subtheme makes the story exciting for the audience, who are the South Slavic singer's primary concern as these songs are generally performed in public places in the community. The format of the oral epic depends entirely on the audience, for their reaction will let the singer know how long their song should be (The Singer of Tales 17). The lengthening and shortening of a song is done by adding or omitting subthemes; an entire theme that may be sacrificed from the plot if a crowd does not seem to be entertained. When an audience is enjoying themselves, themes may be extended. In the 
TranscUlturAl vol. 1, (4) 2011, 47-62.

http://ejournals.library.ualberta.ca/index.php/TC

song "Bećiragić Meho," Lord describes how singer Avdo Međodovic extends the council theme by playing with the agonistic and empathetic: he compares the appearances of contingents of the council, allowing both characters and Međodovic's audience to hail the gloriously clothed and mock the poorly dressed (The Singer of Tales 81). Also vital to a singer when changing the length of a song is ornamentation, which may be considered a theme in itself as it is present in all oral epic songs. Ornamentation is important because it allows a singer to pause the plot by describing things in detail while still entertaining the audience. In the South Slavic epic songs, the features most commonly ornamented are heroes, horses, arms, and castles (The Singer of Tales 86). Excessive attention is paid in the ornamentation of the arming of the hero before he ventures off to do mighty deeds. Lord's study offers passages that demonstrate how the ornamentation of one object will lead to more ornamentation, driving the narrative further. For example, the mention of a golden pistol may result in the singer including its description, how and where it was made, its history, or what usage a pistol has to a hero. ${ }^{2}$

This leads us to the ascending patterns within themes. For example, characters' order of appearance implies their significance, and this is done in a descending pattern; the pattern turns at the last mentioned character, who is revealed to be the most important (The Singer of Tales 92). This demonstrates the South Slavic oral epic's use of a climactic style thematic elements lead up to a cumulative point which signals that one theme is ending and another is about to begin (The Singer of Tales 92). The South Slavic singer introduces the next theme through his logic of narrative - his habitual association of themes - which governs the order of theme execution (The Singer of Tales 96).

One may wonder from where this association of themes derives, as "logic" implies that it is an easy knowledge. The South Slavic oral epic poet acquires this "logic" while and even before learning to sing; having been surrounded by a musical tradition, he becomes aware of certain relationships between themes. These relationships are the result of the influential "tension of essences" - that is, the association of communal concepts that results in the grouping of certain themes or thematic elements (The Singer of Tales 97). Understanding these groupings results in the singer's logic of narrative - what he understands to be a rational and linear sequence. The orderly pattern of themes relieves the

2 Similar descriptive efforts are used in The Iliad, wherein the shield of the hero Achilles is relished for its appearance and history. 
TranscUlturAl vol. 1, (4) 2011, 47-62.

http://ejournals.library.ualberta.ca/index.php/TC

singer of remembering the series of occurrences within a song, while also allowing him to plan ahead (The Singer of Tales 92). He is free to choose where he wants to direct the narrative, or whether he wants to lengthen or shorten the song. This helps the singer compose quickly, thoughtfully, and with organization.

Yet as the tension of essences causes the presence of one theme to demand that of another, so occurs the recycling of themes and descriptions within the South Slavic oral epic. This returns us to the assumption that thematic elements are of a fixed bounty, and that as a result of this fixity, oral epics will inevitably resemble one another. To refute this, we must consider the conditions from which the oral epic came: orality, as in primary oral cultures, makes implausible the recording of knowledge through script, thereby raising the value of knowledge to a status of urgency. In such circumstances, novelty is not a concern whatsoever; the focus becomes the conservative preservation of vital knowledge. The oral epic proved to be the most sufficient way to preserve this knowledge, as cultural information fit easily into both lyric and narrative. Therefore, the art form became a tradition that is inherited by the singer as he learns the craft. In turn, through his participation, the singer retains and re-establishes both the traditional art form and the tradition of the culture.

The resultant information preserved in the oral epic tradition is selected based on how useful and relevant it is to the culture. Consequently, those themes preserved are those close to the human life world: Foley states that "oral poetic traditions encode what we call history, anthropology, folklore, mythology, law, philosophy, medicine, and numerous other disciplines" (How to Read an Oral Poem 28). Lord adds that the oral traditional epic "contains the ideals and values of the society, as well as a concern for the basic problems of both the community and the individual, and how to solve them or to become reconciled to those that are insoluble" (The Singer Resumes the Tale 12). In the South Slavic oral epic theme in which a soldier is armed, the arming may imply that he is a hero, and therefore the act has "overtones of ritual dedication" (The Singer of Tales 88). The arming may also suggest that the man is preparing to accomplish something brave that will make him a hero a process of initiation that leads an audience to become empathetic and admiring (The Singer of Tales 88). When particularly useful information is being presented in an oral narrative, its significance is stressed by increasing and combining oral mnemonic techniques; rituals are often exaggerated, making each crucial act as specific and memorable as possible so that they are well retained. 
TranscUlturAl vol. 1, (4) 2011, 47-62.

http://ejournals.library.ualberta.ca/index.php/TC

Yet what is significant to one culture does not necessarily transfer into another, making the selection of preserved information culture-specific. John Foley's analysis of several different oral traditions - including the ancient Greek, Old English, alongside the comparatively more recent South Slavic tradition - is sensitive to the individual contextual and historical aesthetics of each. Foley believes that academics should consider the synchronic and diachronic contexts of a tradition and the culture behind it, especially since the oral epic is established from and integrated into its originating community (Immanent Art 15). In studying their poetic and thematic elements, he stresses that each tradition has a strong sense of "negotiation of meaning through traditional structures (that) will continue to entail inherent connotation as well; the metonymic contract so long in force and so faithfully observed cannot be suddenly suspended or ignored" (Immanent Art 9). Metonymic denotations of conservative cultural features make an oral epic unique to its derivative culture, and therefore Foley emphasizes that the entire oral epic genre is, what he calls, tradition-dependent (Tradition-dependent 275).

To examine this in relation to the South Slavic oral epic, we turn to John Kolsti, who uses Lord's studies to develop his own on the differences and similarities between the oral traditions of Serbo-Croatia and Albania (South of Serbo-Croatia) (Kolsti v). Although the cultures and languages are somewhat similar, Kolsti is delicate when handling the unique features and elements of each tradition. He observes them through a case study with Salih Ulgjanin, a South Slavic singer who has the ability to sing in both traditions.

Kolsti finds that both traditions share many similar themes that cause them to share story lines, but each has specific subthemes that are derived from the traditional aspect of the culture (Kolsti 108). For example, in "The Song of Captain Garvan" - as sung in both the Serbo-Croatian and Albanian traditions - the following themes occur only within the Serbo-Croatian rendition: the hero's boasting; the hero announcing his quest; and the lady lamenting in the castle (Kolsti 100). These specific themes are used only in the SerboCroatian context because they have been clustered together in association with the SerboCroatian culture, a result of the tension of essences. The exclusion of one will vary or completely disorder the narrative's thematic episodes; indeed, the Albanian version's omission of even the first theme inevitably eliminates all others as the first theme initiates the hero's motivation to rescue the lady (Kolsti 100-103). Therefore, although the two oral 
TranscUlturAl vol. 1, (4) 2011, 47-62.

http://ejournals.library.ualberta.ca/index.php/TC

epic traditions may resemble one another in narrative plot, Kolsti's findings address Foley's concept of tradition-independence: a specific tradition will be determined by the culture particular to it.

All oral epic traditions, no matter the culture from whence it came, share this in common: they retain the tradition and give back to the culture which gave to them. However, as the people of primary oral cultures cannot rely on their memories alone to recall all traditional themes, they require the tool of formula to compose these themes with as little need for memory as possible. Formulas are therefore the backbone of the oral epic if an oral epic poet has the traditional formulas, he can uses them to alter the verse of traditional themes, and will consequently create a traditional story. It is beneficial that formula is fixed in verse (Memory, Fixity, and Genre 459). In this sense, the formula may be considered fixed; however, we must consider that the formulaic line, with all of its fixed elements, has been intentionally formed this way - has been formed in order to preserve the tradition as much as possible.

Foley insists that the distinct formulas of every oral epic tradition will vary in such a way that each tradition demands to be handled differently (Tradition-dependent 275). It is explained that Parry understood oral narrative formulas as he had first studied them - in ancient Grecian texts; all lines of verbal utterance were understood by him to be hexametrical (Tradition-dependent 263). Foley points out the obvious fault in this assumption with regards to Albert Lord: Lord took up Parry's theories and used them to relate the South Slavic oral tradition to the ancient Greek oral tradition, but each tradition's fundament of verse composition - the formula - was rather different (Tradition-dependent 262). The South Slavic formulaic line is a decameter.

In order to understand the South Slavic formula, the specific formula of each tradition is studied for its individual characteristics: Foley measures the South Slavic decasyllable for its syllabicity and internal structure, and then compares it with the Homeric hexasyllable. They are both regular in syllabic meter because of the restrictions that the caesura (break or breath) imposes on them (Tradition-dependent 266). Yet, while the hexasyllable may be split in several ways, the decasyllable's caesura seems bound, imposing restrictions on the South Slavic decasyllable. Homer was therefore thriftier in his phraseology because of his parametric situation, as his hexametric line allowed him more room for alteration in comparison to the South Slavic decametric line (Immanent Art 26). 
TranscUlturAl vol. 1, (4) 2011, 47-62.

http://ejournals.library.ualberta.ca/index.php/TC

Further demonstrating the notion of tradition-independence within the formula is Kolsti's discovery that a Serbo-Croatian song and an Albanian song that possess similar story lines cannot be sung in the same way (Kolsti 87). The traditions are different enough that bilingual and bi-traditional singer Ulgjanin insists that the way in which he composes one oral epic song differs from the other precisely because the formulas are not the same (Kolsti 60). Each tradition has its own methods of composition and therefore, a straightforward and perfect translation is impossible (Kolsti 60). The contrast of conditions between the formulas of the South Slavic, ancient Greek, and Albanian oral traditions justifies Foley's claim that when studying these separate traditions, independent concepts of formula should be established for each (Tradition-dependent 275). This is especially the case considering the historical gap between ancient Greek culture and the comparatively modern South Slavic culture; it is no wonder than a distinction must be made.

In the case of the South Slavic oral epic formula, we re-consider the process through which it is learned. Having grown up around a strong and influential musical tradition, the young South Slavic boy who begins to sing will replicate phrases or entire lines that he recalls, but cannot forever depend on attaching fixed units together as this will not be enough to create an entire song (The Singer of Tales 32). During his learning process, the boy will notice the poetic elements of the oral epic, and though he does not yet understand these elements, as he becomes familiar with them, so he will become sensitive to them. The boy will also notice that in the sung oral epic, thought must be adapted into verse meter and must also correlate with musical meter (The Singer of Tales 31). All of these factors make song composition restricted.

These factors find their domain in each line of the South Slavic oral epic, called the cola (Tradition-dependent 266). The cola has a restrictive structure: it is composed of ten syllables, making it a decasyllable. There is break for a breath between the fourth and fifth syllable, which is called the caesura. The caesura breaks the line up into first and second halves, the first generally four syllables and the second, six syllables. From this line structure, the boy will learn his basic formula pattern; it becomes the foundation from which he learns to compose all future lines of verse as it is adjusted to create different phrases suited to what he wants to say (The Singer of Tales 36). Therefore, all existing lines of verse in the South Slavic oral tradition stem from the basic formula pattern as established by the tradition's 
TranscUlturAl vol. 1, (4) 2011, 47-62.

http://ejournals.library.ualberta.ca/index.php/TC

pioneers and as developed through generations of its bequeathed craftsmen.

The basic formula pattern is composed like a standard sentence, and may possess name, action, time, or place (The Singer of Tales 34, 35). The name provides an opportunity to be aggregative as, to a name may be added an epithet that regards a character's heritage, official title, or city of origin. Elaborate epithets are not used as often because, as each line is only ten syllables, it is easier to be concise (The Singer of Tales 34). Since the subject performs the verb, the length of whichever is placed first will determine the length of the second (The Singer of Tales 34). The mention of time is paired with the verb because it will clarify when the action occurs, and the mention of place will complement a verb because it explains where the action occurs.

Once the boy has thoroughly grasped the basic formula pattern, he can adjust the meaning of it through substitution methods that Parry terms "systems" (The Singer of Tales 35). Systems take on the algebraic structure of $a\{x$. Lord provides an example of the system by charting the phrase, "mounted the horse." The word "horse," which may be expressed in a variety of ways, is represented by the flux variable $x$. With the chosen verb $a-$ to mount - any number of key words may be substituted for the noun $x$ (The Singer of Tales 48). Through this substitution system, a singer can choose to have his character mount $x$ : a horse, a white horse, a brown horse, a donkey - the epic poet is given choice and variation.

However, systems altering the basic formula pattern seem to only permit small adjustments, so that modified phrases resemble the original. Though this would suggest a concept of fixity, in fact, systems actually lend themselves to change through homeostasis, which, with regards to verse, refers to the obsolescence of irrelevant matter. It is a misconception that primary oral cultures are solely concerned with preserving history; "traditions are subject to change: the reforming of old stories, the telling of new ones that may seem much like the old" (The Singer Resumes the Tale 3). Entire fragments of information may be lost if they are no longer considered of use to the human life world, and what does perpetuate are things of immediacy and relevancy. It is also worthwhile to consider that as the tradition was created "by talented singers in some degree of competition with one another, (it) has an abundance of possibilities of continual combination and recombination of its elements into ever changing mosaics" (The Singer Resumes the Tale 29). Competition embeds the tradition with agonistic attributes, therefore propelling 
TranscUlturAl vol. 1, (4) 2011, 47-62.

http://ejournals.library.ualberta.ca/index.php/TC

homeostasis.

One method of homeostatic change within the South Slavic oral tradition is the use of systems to make a new formula. New formulas are composed to adapt to contemporary relevance, refuting the assumption that all content within the South Slavic oral epic is fixed; indeed, Lord notes that "new formulas are made by putting new words, [words that bear then-contemporary cultural connotations,] into old patterns" (The Singer of Tales 43). For example, the older formula Od sultana brǐe ferman dode implies that a ferman has just arrived from the sultan. To modernize this formula, a more modern means of communication, the teljigraf (telegram), can replace the word ferman (ferman) as follows: Od sultana bry̌e teljigraf dođe (The Singer of Tales 44). Here, we seem to have run into a problem: the original word in the formula, ferman, has two syllables whereas teljigraf has three. When using systems, a key word must have a similar meaning to the original word and must have the same number of syllables as the original word so that it fits into the syllabic meter of a line (The Singer of Tales 35). Lord notes that "formulas for communication have been built with either four- or two- syllable words in mind" (The Singer of Tales 44). ${ }^{3}$ The only way to make the word teljigraf fit is to adjust the wording of the line: Pad kad takav teljigraf dolari, bearing threesyllable words. Thus, the meaning and foundational tactic remain, but a new formula and formula pattern are born.

Regardless of the fact that new concepts for formula are possible, the notion of substitution systems and the adjustments they offer in composition still leave the South Slavic art form vulnerable to criticism of mechanicalism. Lord refutes this criticism by claiming that systems are also used in the language of ordinary speech: "the method of language is like that of oral poetry, substitution in the framework of grammar. Without the metrical restrictions of verse, language substitutes one subject for another in the nominative case, keeping the same verb; or keeping the same noun, it substitutes one verb for another" (The Singer of Tales 35). The study of patterns in the verse of the oral epic is identical to the observation of the grammar of poetry, and the singer needs to master this special grammar in order to adjust phrases. Formulas and their poetic grammar "are not mastered by a conscious process of rote memorization, but they are remembered from frequent use and practice" (The Singer Resumes the Tale 11). When a phrase is stabilized with a certain pattern and meaning, and is used so frequently by a singer that he can reproduce and adjust

3 That is, formulas which refer to forms of communication. 
TranscUlturAl vol. 1, (4) 2011, 47-62.

http://ejournals.library.ualberta.ca/index.php/TC

it with ease, then the phrase may be considered a formula (The Singer of Tales 43). Formulas are interiorized, allowing their reflexive use and adjustment; therefore, they "do not exist to make memorization easier, but rather they make memorization unnecessary" (The Singer Resumes the Tale 11).

With regards to the assumption that formulas mechanically fix little phrases together and adjust them through memorized catalogues of appropriate words, the singer's interiorization of formulas proves that mechanicalism is not the domineering method of composition. Interiorization correlates with the South Slavic oral poet's logic of narrative both are traditional modes of reasoning utilized in the formation of the oral epic and both imply that composing such a song does not mean mere picking and choosing out of a catalogue. Lord claims, "were (a singer) merely to learn the phrases and lines from his predecessors, acquiring thus a stock of them, which he would then shuffle about and mechanically put together in juxtaposition as inviolable, fixed units, he would, I am convinced, never become a singer" (The Singer of Tales 37). A true poet of the South Slavic oral epic will take his interiorized formulas and their corresponding patterns, and "by the necessity of performance learn to adjust what he hears and what he wants to say to these patterns" (The Singer of Tales 37).

To develop the concept of interiorization and to further repudiate any claims of mechanical composition, we should consider an example of interiorization in everyday language. If a person wishes to express their gratitude, they do not search through a catalogue of words in their head and piece these words together to do so. They merely say, "thank you," a phrase that has been interiorized in their minds so that they can blurt it out, as Lord states, as a matter of unconscious reflex (Memory, Fixity, and Genre 451). When the South Slavic oral epic poet composes, his formulas are as unconscious to him as reflexive speech, as they have become a part of his natural oral method (Memory, Fixity, and Genre 451).

Just how naturally and reflexively the South Slavic singer can compose a song may be demonstrated by the process through which he learns new songs. Many singers can perform a song a day after having heard it and can also sing very quickly. This is only possible because of their interiorized knowledge; they can pick up themes in a song and use their knowledge of formulas to tweak the theme's features to their own preference. These changes are made via factors through which the basic formulas pattern is adjusted and which 
TranscUlturAl vol. 1, (4) 2011, 47-62.

http://ejournals.library.ualberta.ca/index.php/TC

therefore dictate how each line is formed. These factors are meter, melody, syntax, and acoustics (The Singer of Tales 33).

With meter, trochaic pentameter is prominent in the South Slavic oral epic- a stressed syllable followed by one that is unstressed - but as long as the rest of the line follows in meter, this could deviate to iambic or even dactyl pentameter (The Singer of Tales 37, 38). Metrical changes also require adjustments to a formula pattern because the accented syllables of words should complement the altered meter (The Singer of Tales 38). When considering the syntax of a formula, the second clause of each line always depends on the format of first; the second clause should complement the poetic elements that govern the syntax of the first line (The Singer of Tales 42). Syntactical patterns are governed by the relation of ideas in a series of events. Each line must complement what precedes it, and this is often accomplished by beginning most lines with a conjunction, such as kad (when), te (and), and $p a$ (then). The lines are anaphoric and thus follow an additive format. Such a stratagem is regarded by Lord as a poetic style called enjambement (The Singer of Tales 54), in which the idea of each line is supplemented in the following line. Enjambement helps the singer create connections and relationships between the lines, thus allowing him to "add together a series of actions, moving the story quickly forward" (The Singer of Tales 54).

Much of what governs a line also depends on its acoustic elements - how it sounds and its sound patterns. That the singers pay intense attention to sound is what makes the South Slavic oral epic poetic. In the same passage by Lord, we examine these acoustic elements in the Yugoslav language of the 1950s:

\section{1 "Kud gođ skita za Aliju pita.}

2 Kazaše ga u gradu Kanjidu.

3 Kad tatarin pod Kajnidu dođe,

4 Pa eto ga uz čaršiju prođe,

5 Pa prilazi novom bazdrđanu,

6 Te upita za Alino dvore.

7 Bazdrdan mu dvore ukazao.

8 Kad tatarin na kapiju dođe,

9 Pa zadrma halkom na vratima.

$10 \underline{Z_{\text {veknu }}}$ halka a jeknu kapija" (The Singer of Tales 54) 
TranscUlturAl vol. 1, (4) 2011, 47-62.

http://ejournals.library.ualberta.ca/index.php/TC

Following this example, Lord lists all of the acoustic elements (The Singer of Tales 56, 57). The first and last lines both contain internal rhyme (italicized in the passage): skita and pita; zveknu and jeknu. Kajnidu is the name of the city where the action happens, and to stress this, there is alliteration throughout the passage involving the sound " $k$." The dominating word in the centre of the passage is bazdrdanu (shopkeeper), so there is also " $\mathrm{p}$ $b-z$ " alliteration throughout. There is parallelism of the verb placement (underlined in the passage): in lines three and four, the verb is at end of the line; in lines five and six, it is in the first half; in lines seven and eight, it is at the end of the line; in lines nine and ten, it is in the first half of the line. In lines three and four, dode and prode rhyme. Also, the second half of lines three and four are syllabically and syntactically parallel in the form of preposition, noun, verb: pod Kajnidu dode; uz čaršju prode. Assonance is also prominent in this passage as there are “a-i, “i-a," and "a-u” vowel patterns.

While this kind of detail may seem extraordinary to the unfamiliar eye, it is quite natural for oral epic storytellers to be aware of poetic elements to such proportion and completeness. Even in The Iliad, whenever an important event occurs, there is a myriad of oral acoustic characteristics present that help to complement the lines in assistance with memory. In the South Slavic oral epic, attention to acoustics is one of the ways in which important features of the narrative may be emphasized.

With this in mind, it is important to consider that although singers reproduce the same thematic concepts in order to retain the essential ideas behind it, "singers vary greatly in the comparative stability of the core lines and in the number and character of optional lines... a more or less constant core of lines is ornamented or expanded according to the wishes of the singer at the moment or adapted to fit a particular situation in a particular song” (The Singer Resumes the Tale 213). For example, Lord examines the use of formulas by two singers - Đemail Zogić and Sulejman Makić - and notes that in one passage, Makić uses a formula series twenty-two times and Zogić uses it only twice. This formula then, is obviously preferred by Makić and may be called part of his individual style (The Singer of Tales 64). Each singer may acquire a type of pattern in their style as their frequent use of certain formulas may cause word-for-word recital (Memory, Fixity, and Genre 459). However, patterning is not the same as fixity because formulas are, again, interiorized through constant exposure and usage (Memory, Fixity, and Genre 459). The singer "develops his own passages within measurable and describable parameters" (Memory, Fixity, 
TranscUlturAl vol. 1, (4) 2011, 47-62.

http://ejournals.library.ualberta.ca/index.php/TC

and Genre 460); formula preference develops as a part of his personal repertory.

The repertory of a South Slavic oral poet is his internal gathering of interiorized phrases and themes, and is thus specific to himself as another element of his personal style (The Singer of Tales 78). Having learned lines of verse and their poetic elements so that they become interiorized formulas, and having added these to his repertory, the singer uses his gained repertory as the prime means through which he can learn new songs instantly. When the poet hears a new song, he lets it "sink into his own store of themes and formulas" (Ong 60), contemplating any unfamiliar ideas in relation to his own repertory. He may then make small adjustments to his own interiorized formulas in order to come up with new ones, thus allowing him to create the themes that had been unfamiliar to him in a new song (The Singer of Tales 80).

To demonstrate how this works, we look to talented singer Avdo Međodovic, who was famed for having an enormous repertory of formulas and themes. In the 1930s, he was noted by Milman Parry as having heard a song by Mumin Vlahovljak only once and being immediately able to repeat it. Not only this, but Medodovic elaborated and extended the original song so that, for instance, a passage about the theme of Assembly was extended from 176 lines to 556 lines - over three times longer (The Singer of Tales 79)! This was possible not because Međodovic mechanically chose out of a catalogue, but because he was familiar with all the traditional themes Vlahovljak used in his song. Vlahovljak's themes were interiorized traditional models to which Međodovic could add what he personally knew; his extensive repertory of traditional themes and formulas allowed him to express himself in additional ways and to include additional subthemes (The Singer of Tales 79). Evidently, a vast repertory is significant because it offers the oral epic poet the freedom to compose however they so choose.

As such, without the South Slavic singer's interiorization of everything that the oral epic art form embodies, his effortless weaving in composition would be impossible. The only conception of the cataloguing of formula and theme that can exist in relation to the South Slavic oral epic is in the context of Albert Lord's studies, in which he categorizes formulas and themes as his personal method of organization and comprehension of and within the intricate genre. Subsequent to the analysis of the South Slavic oral tradition should be the comprehension that, “instead of 'repetition' the oral traditional text implies recreation" (Immanent Art 57). As created specifically from and adhering to the South Slavic culture, the traditional South Slavic oral epic song is a paramount and absolutely artistic art form. 
TranscUlturAl vol. 1, (4) 2011, 47-62.

http://ejournals.library.ualberta.ca/index.php/TC

\section{REFERENCES}

Foley, John Miles. How to Read an Oral Poem. Chicago: University of Illinois Press, 2002. Print.

Foley, John Miles. Immanent Art. Indianapolis: Indiana University Press, 1991. Print.

Foley, John Miles. "Tradition-dependent \& -independent Features in Oral Literature (Tradition-dependent)" (1980). Oral Traditional Literature. Ed. John M. Foley. Ohio, Slavica Publishers Inc, 1981. Print.

Kolsti, John. The Bilingual Singer. New York: Garland Publishing, 1990. Print.

Lord, Albert Bates. "Memory, Fixity, and Genre in Oral Traditional Poetries (Memory, Fixity, and Genre)" (1980). Oral Traditional Literature. Ed. John M. Foley. Ohio, Slavica Publishers Inc, 1981. Print.

Lord, Albert Bates. The Singer of Tales. Cambridge: Harvard University Press, 1960. Print. Lord, Albert Bates and Mary Louise Lord. The Singer Resumes the Tale. New York: Cornell University Press, 1995. Print.

Ong, Walter J. Orality and Literacy: The Technologizing of the Word. New York: Routledge, 2002. Print. 